\title{
Impact of Propofol Bolus Administration on the Nociceptive Flexion Reflex Threshold and Bispectral Index in Children-A Case Series
}

\author{
Maximilian David Mauritz ${ }^{1,2, *} \mathbb{D}$, Felix Uhlenberg ${ }^{1,3}{ }^{\text {, Eik Vettorazzi }}{ }^{4} \mathbb{D}^{\mathbb{D}}$, Chinedu Ulrich Ebenebe ${ }^{1}$, \\ Dominique Singer ${ }^{1}$ and Philipp Deindl ${ }^{1}$ \\ 1 Department of Neonatology and Pediatric Intensive Care Medicine, University Children's Hospital, \\ University Medical Center Hamburg-Eppendorf, 20251 Hamburg, Germany; f.uhlenberg@kh-itzehoe.de (F.U.); \\ c.ebenebe@uke.de (C.U.E.); d.singer@uke.de (D.S.); p.deindl@uke.de (P.D.) \\ 2 Department of General Pediatrics and Adolescent Medicine, Children's and Adolescents' Hospital Datteln, \\ Witten/Herdecke University, 45711 Datteln, Germany \\ 3 Department of Pediatrics and Adolescent Medicine, Neonatology and Pediatric Intensive Care Medicine, \\ Itzehoe Medical Center, 25524 Itzehoe, Germany \\ 4 Department of Medical Biometry and Epidemiology, University Medical Center Hamburg-Eppendorf, \\ 20251 Hamburg, Germany; e.vettorazzi@uke.de \\ * Correspondence: m.mauritz@kinderklinik-datteln.de; Tel.: +49-2363-9750
}

check for updates

Citation: Mauritz, M.D.; Uhlenberg, F; Vettorazzi, E.; Ebenebe, C.U.; Singer, D.; Deindl, P. Impact of Propofol Bolus Administration on the Nociceptive Flexion Reflex Threshold and Bispectral Index in Children-A Case Series Children 2021, 8, 639. https://doi.org/ 10.3390 /children 8080639

Academic Editor: Sebastiano A. G. Lava

Received: 8 June 2021

Accepted: 22 July 2021

Published: 27 July 2021

Publisher's Note: MDPI stays neutral with regard to jurisdictional claims in published maps and institutional affiliations.

Copyright: (c) 2021 by the authors. Licensee MDPI, Basel, Switzerland. This article is an open access article distributed under the terms and conditions of the Creative Commons Attribution (CC BY) license (https:// creativecommons.org/licenses/by/ $4.0 /)$.

\begin{abstract}
We analyzed the impact of propofol administration during continuous sedation and analgesia on the nociceptive flexion reflex threshold (NFRT) and Bispectral Index (BIS) in ventilated children. We examined patients who received propofol before planned endotracheal suctioning. Patients were clinically assessed using the modified Face, Legs, Activity, Cry, Consolability (mFLACC) scale and COMFORT-B (Comfort Behavior) scale. We continuously recorded the NFRT and BIS. We recorded 23 propofol administrations in eight patients with an average age of $8.6 \pm 3.5$ years. The median (minimum-maximum) scores for the mFLACC scale and COMFORT-B scale were $0(0-5)$ and 6 (6-17), respectively, before the bolus. The administration of a weight-adjusted propofol bolus of $1.03 \pm 0.31 \mathrm{mg} / \mathrm{kg}$ resulted in an increase in NFRT and burst-suppression ratio; BIS and electromyogram values decreased. Changes from baseline (95\% CI) after propofol bolus administration were BIS -23.9 ( -30.8 to -17.1 ), EMG $-10.5 \mathrm{~dB}$ ( -13.3 to -7.7$)$, SR $14.8 \%$ (5.6 to 24.0$)$ and NFRT $13.6 \mathrm{~mA}$ (5.5 to 21.7). Further studies are needed to determine whether sedated children may benefit from objective pain and sedation monitoring with BIS and NFRT.
\end{abstract}

Keywords: propofol; bispectral index; pain; sedation; nociceptive flexion reflex threshold

\section{Introduction}

Critically ill children experience numerous stressful and potentially painful procedures during intensive care treatment [1]. In addition to benzodiazepines, propofol is widely used as a sedative agent in pediatric intensive care units (PICU). In addition to continuous infusion for short-term sedation, it is used as a bolus administration for shortterm interventions, care facilitation, or extubation [2,3]. Propofol is also frequently used in German intensive care units to facilitate stressful procedures in children, such as endotracheal suctioning [4]. There are no available data in the literature on the use of boluses of propofol in these indications for other countries. It is unclear how additional propofol bolus administrations during continuous sedation and analgesia impact pain reflex thresholds and electroencephalography (EEG) based sedation parameters in children.

\subsection{Clinical Assessment of Pain and Sedation}

It is ideal to avoid painful or stressful procedures in children in the PICU. Nevertheless, if such procedures are unavoidable, then adequate pain management and sedation are paramount. The assessment of pain and sedation in the PICU is a continuing challenge. 
International guidelines for the intensive care treatment of children [5-7] recommend adequate analgesia and sedation based on self-reports [8] and the use of clinical scales when self-reports are not feasible due to preverbal age, cognitive impairment, or impaired communication, for example, due to endotracheal intubation [5].

For clinical assessment of sedation and pain, the Face, Legs, Activity, Cry, Consolability (FLACC) and the COMFORT-B scale are most widely used on PICUs today, respectively [9]. A FLACC score of $>2$ indicates that the patient is experiencing pain [10]. The "modified FLACC" (mFLACC) is adapted for intubated pediatric patients [11]. Adequate sedation according to COMFORT-B ranges from 11 to 22 ; values below and above indicate underand oversedation, respectively [12].

\subsection{Objective Monitoring of Pain and Sedation}

Currently, no technology for measuring pain and sedation in children in the PICU has been widely accepted for clinical use [13]. The polysynaptic spinal nociceptive flexion reflex threshold (NFRT) is a technique that allows the estimation of the degree of analgesia [14]. Nonetheless, this novel analgesia monitor has not yet been validated in pediatric patients.

By applying electrical stimuli to the sural nerve through surface electrodes, the nociceptive flexion reflex (NFR) of the ipsilateral biceps femoris muscle can be measured utilizing a surface electromyogram (EMG). The EMG amplitude of the NFR correlates with the intensity of subjective pain sensation in adults [15]. The stimulus intensity associated with a $50 \%$ probability to elicit a reflex response is defined as the NFRT. In awake patients, the applied stimuli are perceived from not painful to slightly above the pain threshold. The NFRT correlates with the subjective pain threshold of adults [16] and thus can be used as an objective value for the threshold of nociception [14]. NFRT is influenced in a dose-dependent manner by the concentration of opioids, inhalational anesthetics, and propofol in adult patients [17-19]. Regarding the NFRT, there are no published target values or limits for adequate analgesia in children.

The Bispectral Index (BIS) is the most widely used EEG-based sedation and hypnosis monitor in adults. Developed originally for adults, the BIS was investigated in several studies to estimate sedation levels in infants and children with promising results $[20,21]$. The BIS is computed by an unpublished algorithm as a number between 0 (no brain activity) and 100 (awake), using a combination of bispectral EEG analysis, the EEG burst-suppression ratio (SR), and facial EMG data. Lamas and Lopez-Herce recommend BIS values in the range of 60-80 for stable children and 40-60 for unstable children on mechanical ventilation [22]. In a comprehensive study, Malviya et al. evaluated the BIS in children by clinical sedation level and found a mean BIS value of 65 for their lowest sedation level category [23]. BIS values below the above suggest over-sedation of the patient, according to the authors. It should be noted that the BIS is not a validated procedure for sedation monitoring in children. In adults, there is insufficient evidence on the effects of BIS monitoring compared to clinical assessment of sedation in critically ill patients on mechanical ventilation regarding clinical outcomes [24].

International guidelines promote an individual sedation goal for each patient and regular re-evaluation of this goal [5-7]. Influencing factors include the patient's medical condition, circulatory and ventilatory situation, age, and environmental factors. Sedative and analgesic therapy should be titrated according to effect. With suitable clinical assessment scales, a regular re-assessment of the current sedation should be performed.

We recently published results from the "PredIction of Nociception in CHildren" PINCH study, in which we combined continuous BIS and NFRT monitoring with clinical scales to predict noxious responses to endotracheal suctioning in ventilated children [25]. Patients were excluded from the PINCH study prediction analysis if they had received a propofol bolus within $10 \mathrm{~min}$ prior to endotracheal suctioning. This report presents a secondary analysis of those patients excluded from the PINCH study.

We aimed to describe the impact of additional propofol bolus administration during continuous sedation and analgesia on the NFRT and BIS in ventilated children. 


\section{Materials and Methods}

\subsection{Patients}

After obtaining approval from the local ethics committee (Approval PV5210, Ethikkommission der Ärztekammer Hamburg, Germany, 30 March 2016) and written informed consent from both parents, a prospective observational study was performed of mechanically ventilated children in the 14-bed PICU of the University Children's Hospital, University Medical Center Hamburg Eppendorf, Germany between 10 March 2017, and 24 September 2018. According to the local standard protocol, patients received continuous infusions of a combination of midazolam for sedation and an opiate for analgesia. For short postprocedural or short-term post-operative sedation, propofol was infused alone or in combination with an opioid. When clinically indicated, patients also received esketamine or clonidine. Patients excluded from the PINCH study because of bolus administration of propofol are reported in this case series [25]. Exclusion criteria included neuromuscular block, neuromuscular diseases, or trauma to the peripheral or central nervous system. According to the nurse's clinical judgment, of the 30 initially recruited patients, eight received a weight-adjusted bolus of propofol before endotracheal suctioning.

\subsection{Study Protocol}

The nurse in charge and an independent observer (M.D.M., F.U.) clinically assessed the patient using the modified Face, Legs, Activity, Cry, Consolability (mFLACC) scale $[11,26]$ and the COMFORT-B scale $[27,28]$ after a rest period without intervention or disturbance within the preceding $30 \mathrm{~min}$. PICU staff had been trained in the use of the mFLACC scale prior to the study. The COMFORT-B scale was already implemented as part of the local treatment standard. In addition, we continuously recorded the NFRT and BIS. The NFRT was determined using a Paintracker instrument (Dolosys GmbH, Berlin, Germany). The Paintracker uses an automated threshold tracking system that repeatedly applies an electrical stimulation at intervals of $10 \mathrm{~s}$ to the sural nerve and records the electromyographical reflex response of the ipsilateral biceps femoris muscle [29]. The Paintracker automatically alters the electrical stimulation current to determine the NFRT $[16,30]$. We recorded the BIS on a 1-s time scale using the BIS VISTA Monitoring System (Software Revision 1.15, Medtronic, Dublin, Ireland) with pediatric electrodes (BIS Pediatric Sensor, Medtronic, Dublin, Ireland). The BIS was also used to determine the SR and EMG, each of which was provided by the BIS monitor as the percentage of isoelectric EEG over the last $63 \mathrm{~s}$ and as absolute power in the range 70-110 Hz, expressed in decibels (dB), relative to $0.0001 \mu \mathrm{V} 2$. The nursing staff and independent observers were both blinded to the BIS and NFRT monitors. We applied averaging to determine NFRT and BIS values at the baseline time t0 ( -30 to $0 \mathrm{~s}$ ) and time t1 (120 to $180 \mathrm{~s}$ ) relative to propofol injection.

\subsection{Statistical Analysis}

We analyzed the impact of propofol bolus administration on the NFRT, BIS, EMG activity, and SR. We report continuous variables as the mean \pm standard deviation (SD) or median with interquartile range (IQR) and categorical variables as category counts and percentages. Boxplots are displayed as quartiles with $95 \%$ confidence intervals (CIs). Changes in BIS; NFRT, SR and EMG were assessed using a paired-samples T-test and paired Wilcoxon signed-rank test. $p$-values less than 0.05 were considered significant. Statistical analyses were performed using Python (Python Software Foundation, Beaverton, OR, USA) and R 3.6.3 (R Core Team, Vienna, Austria).

\section{Results}

\subsection{Patient Characteristics}

We analyzed 23 cases of propofol bolus administration with a median (minimum-maximum) administration number of $3(1-6)$ per patient in eight patients. Patients were admitted for various reasons to the PICU. Patients were 2.5, 4.9, 6.8, 9.4, 10.3, 10.9, 11.9, and 12.3 years 
old (mean $8.6 \pm 3.5$ years). They were on mechanical ventilation for a total of $7.9 \pm 5.5$ days (Table 1). None of the patients died during their course of treatment in the PICU.

Table 1. Clinical characteristics of the included patients.

\begin{tabular}{|c|c|}
\hline Characteristics & $n=8$ \\
\hline Male & $5(62.5)$ \\
\hline Female & $3(37.5)$ \\
\hline Age, years & $8.6 \pm 3.5$ \\
\hline Bodyweight, $\mathrm{kg}$ & $24.0 \pm 8.9$ \\
\hline Time on mechanical ventilation, days & $7.9 \pm 5.5$ \\
\hline Length of PICU stay, days & $14.1 \pm 9.7$ \\
\hline \multicolumn{2}{|c|}{ Mode of mechanical ventilation } \\
\hline SIMV & $6(75)$ \\
\hline BIPAP & $2(25)$ \\
\hline \multicolumn{2}{|c|}{ Diagnostic group } \\
\hline Non-cardiac post-operative & $4(50)$ \\
\hline Miscellaneous (including injury) & $3(37.5)$ \\
\hline Cardiac post-operative & $1(12.5)$ \\
\hline
\end{tabular}

PICU: pediatric intensive care unit; SIMV: synchronized intermittent mandatory ventilation; BIPAP: bilevel positive airway pressure. Continuous variables are shown as the mean \pm standard deviation, counts as $n$ ( $\%$ of all included patients).

\subsection{Impact of Propofol on BIS and NFRT}

The mean $\pm \mathrm{SD}$ administered propofol dose was $1.03 \pm 0.31 \mathrm{mg} / \mathrm{kg}$ (range $0.48-2.04 \mathrm{mg} / \mathrm{kg}$ ) in these observations. The median (minimum-maximum) clinical pain and sedation score assessed by the independent observer before the propofol bolus (t0) was $0(0-5)$ for the mFLACC scale and $6(6-17)$ for the COMFORT-B scale. The baseline values (median, IQR) of the sedation and pain monitoring were BIS 51.9, IQR 31.1-72.3; EMG activity $32.3 \mathrm{~dB}$, IQR 30.4-39.5 dB; SR 0\%, IQR 0-0\% and NFRT $29.7 \mathrm{~mA}$, IQR 10.2-45.5 mA, respectively. After propofol bolus administration (t1), the BIS, EMG, SR, and NFRT values (median, IQR) were 16.9, IQR 14.3-41.6; $23.1 \mathrm{~dB}$, IQR 21.5-25.3 dB; 0\%, IQR 0-29 \% and 42.2 mA, IQR 24.1-62.9 mA, respectively (Figure 1). Both BIS and EMG values decreased within 1 min following propofol bolus administration, whereas the SR and NFRT peaked 2 min after the propofol bolus. Changes from baseline $(95 \% \mathrm{CI})$ after propofol bolus administration (t1) were $-23.9(-30.8$ to -17.1$),-10.5(-13.3$ to -7.7$), 14.8$ (5.6 to 24.0) and 13.6 (5.5 to 21.7) for BIS, EMG, SR, and NFRT respectively. There was a statistically significant difference $(p<0.05)$ between all values before $(\mathrm{t} 0)$ and after propofol administration ( $\mathrm{t} 1$ ). Changes from baseline values over time are shown in Figure 2 with respective $95 \%$ CIs. We assessed the changes in parameters across the different time points using a paired Wilcoxon signed-rank test. The analysis showed a strong effect for BIS $(\mathrm{z}=-4.2, p<0.01, \mathrm{n}=23$, effect size $\mathrm{r}=-0.87)$, EMG $(\mathrm{z}=-4.2, p<0.01, \mathrm{n}=23, \mathrm{r}=-0.98)$, $\mathrm{SR}(\mathrm{z}=-3.1, p<0.01, \mathrm{n}=23, \mathrm{r}=-0.72)$ and NFRT $(\mathrm{z}=-3.3, p<0.01, \mathrm{n}=23, \mathrm{r}=-0.77)$. 

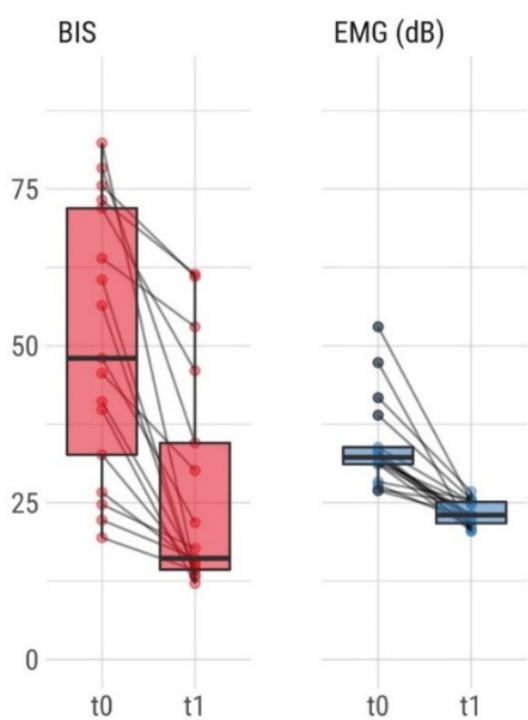

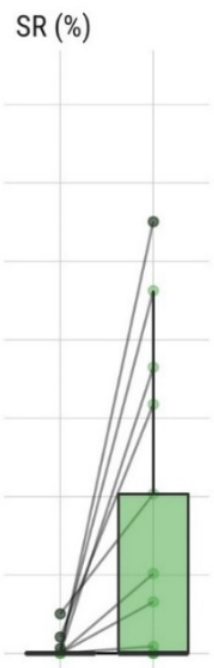

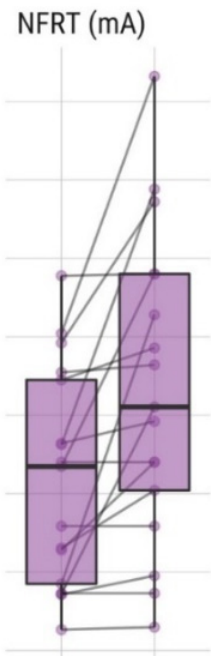

t0 t1

Figure 1. Boxplot showing the distribution of bispectral index (BIS), electromyogram (EMG), suppression ratio (SR), and nociceptive flexion reflex threshold (NFRT) before (t0) and after (t1) propofol bolus administration. Horizontal lines indicate changes during individual measurements.
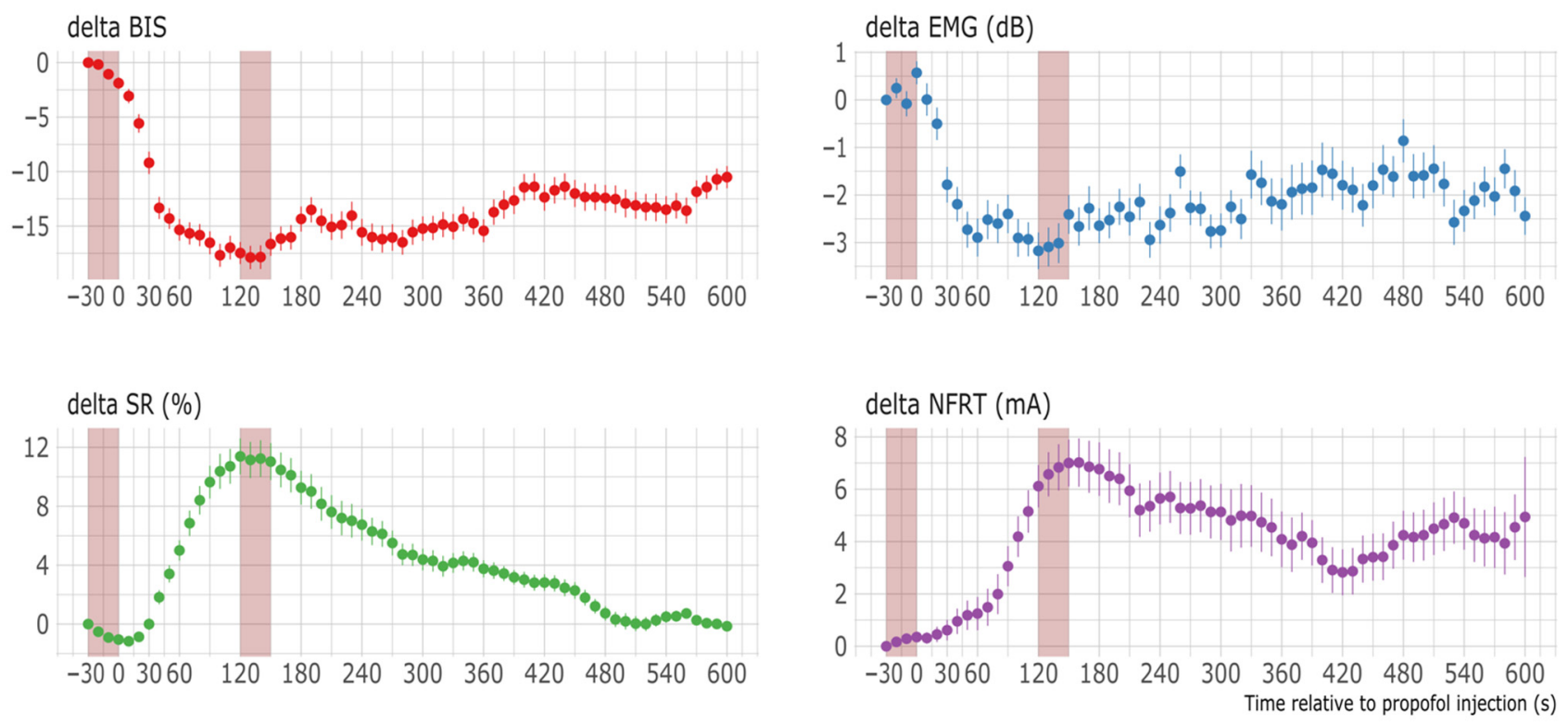

Figure 2. Changes from baseline values (delta) of Bispectral Index (BIS), electromyogram (EMG), suppression ratio (SR), and nociceptive flexion reflex threshold (NFRT) over time with respective $95 \%$ CIs. Propofol was administered at $0 \mathrm{~s}$. The red areas mark the periods $\mathrm{t} 0$ and $\mathrm{t} 1$, in which the values for BIS, EMG, SR, and NFRT were averaged.

\section{Discussion}

Propofol bolus administration had a significant impact on both the NFRT and BIS in ventilated children. After propofol injection, the NFRT and SR increased, and the BIS and EMG decreased.

Based on their clinical judgment, each nurse in charge determined whether a bolus dose of propofol should be administered, as intended in the original study protocol. The combination of low BIS values (median 51.9, IQR 31.1-72.2) and low COMFORT-B scores (median; minimum-maximum: 6; 6-17) indicates that patients were already profoundly sedated before they received the additional propofol bolus. Consequently, we observed very low BIS values (median 16.9, IQR 14.3-41.6) and a high amount of burst suppressions after propofol administration, suggesting very deep sedation of the patients [22,23]. 
The assessment of adequate sedation and analgesia, especially in pediatric patients, is challenging. Clinical judgment is strongly dependent on the assessor's experience, and even when clinical scales are used, there is a relevant risk of bias [31]. In addition, pain experiences correlate with the development of chronic pain syndromes, post-traumatic stress disorder (PTSD), and low health-related quality of life [7]. Although over-sedation poses a considerably greater risk here, under-sedation has also long been suspected of promoting PTSD. In this context, caregivers tend to avoid under-sedation, especially in children. This intention, in turn, may increase the risk of over-sedation, especially in already deeply sedated patients [32].

We observed a significant effect of propofol on the NFRT in ventilated children. Opioids increase the NFRT in a dose-dependent manner, reflecting the spinal analgesia level. Propofol has a similar effect on the NFRT in adults [33]. This effect has not yet been described in children. Propofol is often used for short-term sedation in PICUs [2,3,7] and procedural sedation inside and outside the intensive care unit $[34,35]$. Despite its lack of analgesic effect, it is also frequently used in German PICUs to facilitate stressful procedures, such as endotracheal suctioning [4]. In adults, it has been shown to possibly suppress neurons in the ventral spinal cord, resulting in increased NFRT [36]. Ongoing research investigates whether propofol influences peripheral (dorsal horn) and central nociception or whether it only suppresses the motor reflex response to a painful stimulus [19]. The absence of movement response to a painful intervention cannot always be interpreted as a lack of nociception [14]. On the contrary, also under high doses of propofol, including burst suppression EEG and high NFRTs, cortical responses have been provoked during intense noxious stimuli [37].

We also observed a significant decrease in BIS values after propofol administration in our patients. With increasing anesthetic dosage, the high-frequency EEG components decrease, and the low-frequency components increase, indicating central nervous system attenuation. This effect is primarily reflected in the BetaRatio and SynchFastSlow analysis of the BIS algorithm [38], explaining the decrease in BIS values in our patients. Since the original algorithm is unpublished, it is unclear whether the BIS algorithm also uses EMG activity as a surrogate parameter in certain areas. Other studies have demonstrated similar effects on the BIS [39]. The presence of burst suppression during sedation has been shown to correlate with delirium risk, prolonged hospital stay, cognitive impairment after treatment, and increased mortality in adults [40]. Recent studies investigating risk factors for emergence delirium in pediatric patients could not confirm a relationship between intra-operative burst suppression and post-operative delirium [41]. However, studies regarding the effects of deep sedation in intensive care patients are lacking.

Each nurse was blinded to the BIS and NFRT measurements in our study and decided whether an additional propofol bolus should be administered before endotracheal suctioning based on their clinical judgment alone. This approach resulted in very deep sedation in our patients. Concerns that a potentially unpleasant maneuver such as endotracheal suctioning might result in the child's arousal might have overruled the nurses' clinical patient assessment.

EEG-based sedation monitoring may help to distinguish deep sedation from oversedation by reflecting brain activity. The same is true for the analgesia level reflected by the NFRT. We observed that in children with low mFLACC pain scores, including an absent pain response to stimulation, the NFRT still increased after propofol bolus administration. Hence, further studies in objective monitoring of sedation and pain are needed to validate their use in capturing analgesia and sedation regions that are not accessible by clinical scores. Nevertheless, these tools may offer a potential advantage for managing pain and sedation in children treated in the PICU.

However, especially in deeply sedated children, who cannot express themselves, assessments based on clinical scales alone can be imprecise [21]. Therefore, randomized controlled trials should explore whether objective and accurate pain and sedation monitor- 
ing can potentially improve PICU patient outcomes, especially in avoiding over-sedation and its potential adverse effects.

\section{Limitations}

The sample of patients recruited in this study was small and heterogeneous regarding age, underlying disease, and medication. Half of the patients shown in this case series were admitted to the PICU postoperatively; this sample does not represent the broad spectrum of a pediatric intensive care unit. We performed multiple measurements in the patients, which were considered in the statistical analysis using paired-samples T-test and paired Wilcoxon signed-rank test. We defined the time point after propofol injection (t1) as the period of 120-150 s after administration. This definition was based on the clinical pharmacokinetics of propofol and corresponds with maximal BIS change after propofol injection in children for this period [39]. Due to the original study's design, we did not interview the nursing staff about the factors that motivated their decision to administer propofol as a bolus. Further studies are needed to determine whether sedated children may benefit from objective and accurate pain and sedation monitoring.

\section{Conclusions}

Based on the clinical judgment of nurses, ventilated children in our sample received a propofol bolus prior to endotracheal suctioning. Propofol injection significantly increased the NFRT and decreased the BIS, with a high SR and low EMG activity. Only the baseline values of BIS and NFRT had a significant impact on the respective values after propofol injection. Both tools are not yet validated for monitoring pain and sedation in the PICU, and further studies are needed to validate their use.

Author Contributions: Conceptualization, M.D.M., F.U., C.U.E. and P.D.; methodology, M.D.M., F.U. and P.D.; validation, E.V. and P.D.; formal analysis, M.D.M., F.U., E.V. and P.D.; investigation, M.D.M. and F.U.; resources, M.D.M., F.U., C.U.E. and P.D.; data curation, M.D.M., F.U., E.V. and P.D.; writing - original draft preparation, M.D.M., F.U. and P.D.; writing-review and editing, M.D.M., F.U., C.U.E., D.S. and P.D.; visualization, M.D.M., F.U. and P.D.; supervision, D.S. and P.D.; project administration, D.S. and P.D.; funding acquisition, P.D. All authors have read and agreed to the published version of the manuscript.

Funding: The study was supported by the foundation 'Hamburg macht Kinder gesund e.V.'. The foundation had no role in the design and conduct of the study.

Institutional Review Board Statement: The study was conducted according to the guidelines of the Declaration of Helsinki and approved by the local ethics committee (PV5210, Ethikkommission der Ärztekammer Hamburg, Germany) on 30 March 2016.

Informed Consent Statement: Informed consent was obtained from both parents of subjects involved in the study.

Data Availability Statement: The data presented in this study are available on request from the corresponding author. The data are not publicly available due to privacy restrictions.

Acknowledgments: The authors thank Dolosys $\mathrm{GmbH}$, Berlin, for their technical support with the Paintracker. This study was supported by the "Hamburg macht Kinder gesund e.V." foundation.

Conflicts of Interest: The authors declare no conflict of interest.

\section{References}

1. Stevens, B.J.; Abbott, L.K.; Yamada, J.; Harrison, D.; Stinson, J.; Taddio, A.; Barwick, M.; Latimer, M.; Scott, S.D.; Rashotte, J.; et al. Epidemiology and Management of Painful Procedures in Children in Canadian Hospitals. Can. Med. Assoc. J. 2011, 183, E403-E410. [CrossRef] [PubMed]

2. Bhalala, U.S.; Patel, A.; Thangavelu, M.; Sauter, M.; Appachi, E. Propofol Infusion Is a Feasible Bridge to Extubation in General Pediatric Intensive Care Unit. Front. Pediatr. 2020, 8, 255. [CrossRef] [PubMed] 
3. Patel, A.K.; Trujillo-Rivera, E.; Faruqe, F.; Heneghan, J.A.; Workman, T.E.; Zeng-Treitler, Q.; Chamberlain, J.; Morizono, H.; Kim, D.; Bost, J.E.; et al. Sedation, Analgesia, and Neuromuscular Blockade: An Assessment of Practices From 2009 to 2016 in a National Sample of 66,443 Pediatric Patients Cared for in the ICU. Pediatr. Crit. Care Med. 2020, 21, e599-e609. [CrossRef]

4. Kruessell, M.A.; Udink Ten Cate, F.E.; Kraus, A.-J.; Roth, B.; Trieschmann, U. Use of Propofol in Pediatric Intensive Care Units. Pediatr. Crit. Care Med. 2012, 13, e150-e154. [CrossRef]

5. Harris, J.; Ramelet, A.-S.; Van Dijk, M.; Pokorna, P.; Wielenga, J.; Tume, L.; Tibboel, D.; Ista, E. Clinical Recommendations for Pain, Sedation, Withdrawal and Delirium Assessment in Critically Ill Infants and Children: An ESPNIC Position Statement for Healthcare Professionals. Intensive Care Med. 2016, 42, 972-986. [CrossRef]

6. Playfor, S.; Jenkins, I.; Boyles, C.; Choonara, I.; Davies, G.; Haywood, T.; Hinson, G.; Mayer, A.; Morton, N.; Ralph, T.; et al. Consensus Guidelines on Sedation and Analgesia in Critically Ill Children. Intensive Care Med. 2006, 32, 1125-1136. [CrossRef] [PubMed]

7. Devlin, J.W.; Skrobik, Y.; Gélinas, C.; Needham, D.M.; Slooter, A.J.C.; Pandharipande, P.P.; Watson, P.L.; Weinhouse, G.L.; Nunnally, M.E.; Rochwerg, B.; et al. Clinical Practice Guidelines for the Prevention and Management of Pain, Agitation/Sedation, Delirium, Immobility, and Sleep Disruption in Adult Patients in the ICU. Crit. Care Med. 2018, 46, e825-e873. [CrossRef] [PubMed]

8. Raja, S.N.; Carr, D.B.; Cohen, M.; Finnerup, N.B.; Flor, H.; Gibson, S.; Keefe, F.J.; Mogil, J.S.; Ringkamp, M.; Sluka, K.A.; et al. The Revised International Association for the Study of Pain Definition of Pain: Concepts, Challenges, and Compromises. Pain 2020, 161, 1976-1982. [CrossRef] [PubMed]

9. Laures, E.; LaFond, C.; Hanrahan, K.; Pierce, N.; Min, H.; McCarthy, A.M. Pain Assessment Practices in the Pediatric Intensive Care Unit. J. Pediatr. Nurs. 2019, 48, 55-62. [CrossRef] [PubMed]

10. Bai, J.; Hsu, L.; Tang, Y.; Van Dijk, M. Validation of the COMFORT Behavior Scale and the FLACC Scale for Pain Assessment in Chinese Children after Cardiac Surgery. Pain Manag. Nurs. 2012, 13, 18-26. [CrossRef] [PubMed]

11. Johansson, M.; Kokinsky, E. The COMFORT Behavioural Scale and the Modified FLACC Scale in Paediatric Intensive Care. Nurs. Crit. Care 2009, 14, 122-130. [CrossRef]

12. Ista, E.; van Dijk, M.; Tibboel, D.; de Hoog, M. Assessment of Sedation Levels in Pediatric Intensive Care Patients Can Be Improved by Using the COMFORT “Behavior" Scale. Pediatr. Crit. Care Med. 2005, 6, 58-63. [CrossRef]

13. Kudchadkar, S.R.; Yaster, M.; Punjabi, N.M. Sedation, Sleep Promotion, and Delirium Screening Practices in the Care of Mechanically Ventilated Children. Crit. Care Med. 2014, 42, 1592-1600. [CrossRef]

14. Jakuscheit, A.; Posch, M.J.; Gkaitatzis, S.; Neumark, L.; Hackbarth, M.; Schneider, M.; Lichtner, G.; Baars, J.H.; Von Dincklage, F. Utility of Nociceptive Flexion Reflex Threshold and Bispectral Index to Predict Movement Responses under Propofol Anaesthesia. Somatosens. Mot. Res. 2017, 34, 1-6. [CrossRef]

15. Rhudy, J.L.; Green, B.A.; Arnau, R.C.; France, C.R. Taxometric Analysis of Biceps Femoris EMG Following Electrocutaneous Stimulation over the Sural Nerve: Determining the Latent Structure of the Nociceptive Flexion Reflex (NFR). Int. J. Psychophysiol. 2008, 69, 18-26. [CrossRef]

16. Sandrini, G.; Serrao, M.; Rossi, P.; Romaniello, A.; Cruccu, G.; Willer, J.C. The Lower Limb Flexion Reflex in Humans. Prog. Neurobiol. 2005, 77, 353-395. [CrossRef] [PubMed]

17. Von Dincklage, F.; Hackbarth, M.; Mager, R.; Rehberg, B.; Baars, J.H. Monitoring of the Responsiveness to Noxious Stimuli during Anaesthesia with Propofol and Remifentanil by Using RIII Reflex Threshold and Bispectral Index. Br. J. Anaesth. 2010, 104, 201-208. [CrossRef]

18. Von Dincklage, F.; Velten, H.; Rehberg, B.; Baars, J.H. Monitoring of the Responsiveness to Noxious Stimuli during Sevoflurane Mono-Anaesthesia by Using RIII Reflex Threshold and Bispectral Index. Br. J. Anaesth. 2010, 104, 740-745. [CrossRef] [PubMed]

19. Baars, J.H.; Mager, R.; Dankert, K.; Hackbarth, M.; Von Dincklage, F.; Rehberg, B. Effects of Sevoflurane and Propofol on the Nociceptive Withdrawal Reflex and on the H Reflex. Anesthesiology 2009, 111, 72-81. [CrossRef] [PubMed]

20. Sadhasivam, S.; Ganesh, A.; Robison, A.; Kaye, R.; Watcha, M.F. Validation of the Bispectral Index Monitor for Measuring the Depth of Sedation in Children. Anesth. Analg. 2006, 102, 383-388. [CrossRef] [PubMed]

21. Giordano, V.; Deindl, P.; Goeral, K.; Czaba, C.; Weninger, M.; Berger, A.; Olischar, M.; Werther, T. The Power of N-PASS, AEEG, and BIS in Detecting Different Levels of Sedation in Neonates: A Preliminary Study. Paediatr. Anaesth. 2018, 28, 1096-1104. [CrossRef]

22. Lamas, A.; López-Herce, J.; Sancho, L.; Mencía, S.; Carrillo, Á.; Santiago, M.J.; Martínez, V. Responsiveness to Stimuli of Bispectral Index, Middle Latency Auditory Evoked Potentials and Clinical Scales in Critically Ill Children. Anaesthesia 2008, 63, 1296-1301. [CrossRef] [PubMed]

23. Malviya, S.; Voepel-Lewis, T.; Tait, A.R.; Watcha, M.F.; Sadhasivam, S.; Friesen, R.H. Effect of Age and Sedative Agent on the Accuracy of Bispectral Index in Detecting Depth of Sedation in Children. Pediatrics 2007, 120, e461-e470. [CrossRef] [PubMed]

24. Shetty, R.M.; Bellini, A.; Wijayatilake, D.S.; Hamilton, M.A.; Jain, R.; Karanth, S.; Namachivayam, A. BIS Monitoring versus Clinical Assessment for Sedation in Mechanically Ventilated Adults in the Intensive Care Unit and Its Impact on Clinical Outcomes and Resource Utilization. Cochrane Database Syst. Rev. 2018, 2, CD011240. [CrossRef]

25. Mauritz, M.D.; Uhlenberg, F.; Bashir-Elahi, D.; Werther, T.; Gottschalk, U.; Ebenebe, C.U.; Bergers, M.; Giordano, V.; Vettorazzi, E.; Singer, D.; et al. Prediction of Nociception in Children Using the Nociceptive Flexion Reflex Threshold and the Bispectral Index-A Prospective Exploratory Observational Study. Pediatr. Crit. Care Med. 2021. Publish Ahead of Print. [CrossRef] 
26. Merkel, S.I.; Voepel-Lewis, T.; Shayevitz, J.R.; Malviya, S. The FLACC: A Behavioral Scale for Scoring Postoperative Pain in Young Children. Pediatr. Nurs. 1997, 23, 293-297.

27. Carnevale, F.A.; Razack, S. An Item Analysis of the COMFORT Scale in a Pediatric Intensive Care Unit. Pediatr. Crit. Care Med. 2002, 3, 177-180. [CrossRef]

28. Ambuel, B.; Hamlett, K.W.; Marx, C.M.; Blumer, J.L. Assessing Distress in Pediatric Intensive Care Environments: The COMFORT Scale. J. Pediatr. Psychol. 1992, 17, 95-109. [CrossRef]

29. Von Dincklage, F.; Hackbarth, M.; Schneider, M.; Baars, J.H.; Rehberg, B. Introduction of a Continual RIII Reflex Threshold Tracking Algorithm. Brain Res. 2009, 1260, 24-29. [CrossRef] [PubMed]

30. Willer, J.C. Comparative Study of Perceived Pain and Nociceptive Flexion Reflex in Man. Pain 1977, 3, 69-80. [CrossRef]

31. Giordano, V.; Edobor, J.; Deindl, P.; Wildner, B.; Goeral, K.; Steinbauer, P.; Werther, T.; Berger, A.; Olischar, M. Pain and Sedation Scales for Neonatal and Pediatric Patients in a Preverbal Stage of Development. JAMA Pediatr. 2019, 173, 1186-1197. [CrossRef]

32. Vet, N.J.; Ista, E.; De Wildt, S.N.; Van Dijk, M.; Tibboel, D.; De Hoog, M. Optimal Sedation in Pediatric Intensive Care Patients: A Systematic Review. Intensive Care Med. 2013, 39, 1524-1534. [CrossRef] [PubMed]

33. Von Dincklage, F.; Send, K.; Hackbarth, M.; Rehberg, B.; Baars, J.H. Comparison of the Nociceptive Flexion Reflex Threshold and the Bispectral Index as Monitors of Movement Responses to Noxious Stimuli under Propofol Mono-Anaesthesia. Br. J. Anaesth. 2009, 102, 244-250. [CrossRef] [PubMed]

34. Kamat, P.P.; McCracken, C.E.; Gillespie, S.E.; Fortenberry, J.D.; Stockwell, J.A.; Cravero, J.P.; Hebbar, K.B. Pediatric Critical Care Physician-Administered Procedural Sedation Using Propofol. Pediatr. Crit. Care Med. 2015, 16, 11-20. [CrossRef] [PubMed]

35. Playfor, S.D.; Venkatesh, K. Current Patterns of Propofol Use in PICU in the United Kingdom and North America. Pediatr. Anaesth. 2004, 14, 501-504. [CrossRef]

36. Kim, J.; Yao, A.; Atherley, R.; Carstens, E.; Jinks, S.L.; Antognini, J.F. Neurons in the Ventral Spinal Cord Are More Depressed by Isoflurane, Halothane, and Propofol Than Are Neurons in the Dorsal Spinal Cord. Anesth. Analg. 2007, 105, 1020-1026. [CrossRef]

37. Lichtner, G.; Auksztulewicz, R.; Kirilina, E.; Velten, H.; Mavrodis, D.; Scheel, M.; Blankenburg, F.; Von Dincklage, F. Effects of Propofol Anesthesia on the Processing of Noxious Stimuli in the Spinal Cord and the Brain. Neuroimage 2018, 172. [CrossRef] [PubMed]

38. Rampil, I.J.; Kim, J.-S.; Lenhardt, R.; Negishi, C.; Sessler, D.I. Bispectral EEG Index during Nitrous Oxide Administration. Anesthesiology 1998, 89, 671-677. [CrossRef] [PubMed]

39. Wang, F.; Zhang, J.; Yu, J.; Tian, M.; Cui, X.; Wu, A. Variation of Bispectral Index in Children Aged 1-12 Years under Propofol Anesthesia: An Observational Study. BMC Anesthesiol. 2019, 19, 145. [CrossRef] [PubMed]

40. Watson, P.L.; Shintani, A.K.; Tyson, R.; Pandharipande, P.P.; Pun, B.T.; Ely, E.W. Presence of Electroencephalogram Burst Suppression in Sedated, Critically Ill Patients Is Associated with Increased Mortality. Crit. Care Med. 2008, 36, $3171-3177$. [CrossRef]

41. Koch, S.; Stegherr, A.-M.; Rupp, L.; Kruppa, J.; Prager, C.; Kramer, S.; Fahlenkamp, A.; Spies, C. Emergence Delirium in Children Is Not Related to Intraoperative Burst Suppression-Prospective, Observational Electrography Study. BMC Anesth. 2019, 19, 1-7. [CrossRef] [PubMed] 